\title{
Preliminary selection for potential probiotic Bifidobacterium isolated from subjects of different Chinese ethnic groups and evaluation of their fermentation and storage characteristics in bovine milk
}

\author{
W. J. Liu, Y. F. Chen, L. Y. Kwok, M. H. Li, T. Sun, C. L. Sun, X. N. Wang, T. Dan, Menghebilige, H. P. Zhang, \\ and T. S. Sun ${ }^{1}$ \\ Key Laboratory of Dairy Biotechnology and Engineering, Ministry of Education P.R.C. Inner Mongolia Agricultural University; \\ Dairy Processing Laboratory of National Dairy Production Technology and Research Center, Inner Mongolia, Hohhot, 010018, China
}

\begin{abstract}
A total of 29 strains of Bifidobacterium were isolated from 18 samples of human feces in different ethnic minority regions of China. All isolates were identified as Bifidobacterium longum (9 strains) and Bifidobacterium pseudocatenulatum (20 strains) based on 16S rRNA gene sequencing and phylogenetic analysis. These strains were preliminarily tested for their suitability to become probiotics by assessing their ability to survive adequately at low $\mathrm{pH}$ conditions and their tolerance of different concentrations of bile salts and simulated gastrointestinal juices. In vitro tests were sequentially used to predict the survival of these strains in the simulated conditions in the human gastrointestinal tract. These strains were first exposed to $\mathrm{pH} 2.5$ for $3 \mathrm{~h}$, and 7 out of the 29 strains were discriminated from the others by their high survival rates. Out of these 7 strains, 4 were found to grow and survive well at an even lower $\mathrm{pH}$ of 2.0 and in high bile salt concentration. Apart from the gastrointestinal survival capacity, both fermentation efficiency and storage characteristics are important criteria for selecting for suitable potential probiotic strains. Therefore, the fermentation efficiency in bovine milk and the bacterial viability during the storage in the resultant fermented milk were also evaluated for these 4 selected strains. In this study, we isolated and identified 29 novel Bifidobacterium strains. Based on our initial evaluation, at least 4 of them may serve as valuable resources for further dairy probiotic strain selection.
\end{abstract}

Key words: Bifidobacterium, human origin, potential probiotic, fermentation and storage characteristics

\section{INTRODUCTION}

China is a large country noted for its dense population and vast territory, and it has altogether 56 ethnic

Received January 16, 2013.

Accepted July 29, 2013.

${ }^{1}$ Corresponding author: sts9940@sina.com groups. The majority of the population belongs to the Han ethnic group (91.95\%; total of $1,159.4$ million), and the other 55 ethnic groups are customarily referred to as the national minorities (together making up 8.41\%; total of 106.43 million). The national minorities, although fewer in number, are scattered over a vast area, mainly distributed in the border regions from northeast China to north, northwest, and southwest China. The largest is the 12 million-strong Zhuang ethnic group in southwestern China. Yunnan Province, home to more than 20 ethnic groups, has the greatest diversity of minority people in China. Individual ethnic minority groups are characterized by having distinct physical and cultural traits, including their lifestyles, customs, eating habits, and diets. These differences may contribute to the creation of a rich and distinctive spectrum of intestinal microflora in the different ethnic groups. Therefore, it would be both important and of great scientific interest to identify and to screen for potential probiotic Bifidobacterium strains from these ethnic populations. The successful identification of probiotic strains not only enhances our understanding on the distinctive gut microbiota composition in the different ethnic groups, but also opens the opportunities for exploitation of novel probiotic strains that might be suitable for Chinese human intestinal tract physiological characteristics.

Probiotic bacteria are defined as "live microorganisms that when administered in adequate amounts confer a health benefit on the host" (FAO/WHO, 2001). Bifidobacteria are gram-positive, saccharolytic, intestinal anaerobes, representing up to 25 and $80 \%$ of the cultivable fecal bacteria in adults and in infants, respectively (Picard et al., 2005). Bifidobacterium, as a probiotic agent in human food, has been widely used because of its generally recognized as safe (GRAS) status. Some strains have been used in fermented dairy products and exert a wide range of beneficial health effects, including the prevention or alleviation of infectious diarrhea, the inhibition of growth of pathogens and harmful bacte- 
ria, the modulation of the local and systemic immune responses, and so on. However, the viability of some of these probiotic strains for food use sharply decreases during the product shelf life. Moreover, many of these bacteria may be killed during their transit through the acidic conditions of the stomach and be degraded or inactivated by hydrolytic enzymes and bile salts in the small intestine (Playne, 1994). Therefore, the gastrointestinal survival capacity is considered as an important criterion for the initial selection for potential probiotic strains.

Fermented foods are major carriers of probiotic bacteria with positive health effect. In particular, fermented dairy products have been increasingly attracting the attention of consumers. In Japan, bifidobacteriacontaining products are very popular and one-third of the total yogurt sales involve these products. In France, $11 \%$ of all yogurts sold contain added bifidobacteria (Shah, 2000). Thus, screening bifidobacterial strains with potential probiotic functions is regarded as a major basic but important task for industrial application. It is known that the resistance to acid and bile salts varies widely among bifidobacterial species, even at the level of the strain (Liu et al., 2007). Additionally, a rapid decline of viable counts in dairy food and other fermented probiotic products has been observed during the shelf life and during transit through the intestinal tract (Conway et al., 1987; Shah and Jelen, 1990; Dave and Shah, 1996). Therefore, it is necessary to select the right vehicle for the delivery of probiotics to ensure that these bacteria remain viable throughout the product shelf life and overcome the physical and chemical barriers in the gastrointestinal tract (Samona and Robinson, 1991; Vinderola et al., 2000; Del Piano et al., 2006). Adding proper probiotic strains into the fermented dairy products not only provides healthpromoting effects, but also affects the physicochemical and microbial properties of the products, such as $\mathrm{pH}$ value, viscosity, syneresis, organic acid contents, and viable counts of the probiotics (Wang et al., 2009). In this work, 29 bifidobacteria were isolated from fecal samples of subjects from different Chinese minority ethnic groups; fermentation and storage characteristics of these selected strains in bovine milk were also evaluated.

\section{MATERIALS AND METHODS}

\section{Sample Collection}

Eighteen fecal samples were collected from 18 counties in 6 provinces of China, including Henan, Sichuan, Tibet, Yunnan, Xinjiang, and Inner Mongolia. The volunteers recruited for this study were from different ethnic groups such as Han (distributed throughout the country and is the major population of China), Tujia (an ethnic group population, distributed widely in $\mathrm{Hu}-$ nan, Hubei, Guizhou, and Sichuan Provinces; believe in the great influence of gods and ancestors, and live on agriculture and the fishing industry), Bai (an ethnic group population; inhabit the province of Yunnan; are masters of artistic creativity and favor white clothes and decorations), Tibetan (mostly live in the Tibetan Autonomous Region, and the people believe in Tibetan Buddhism, which is also called Lamaism; butter tea, mutton, and beef are their staple foods), Kazak (mainly dwell in Xinjiang, Gansu, and Qinghai; the staple foods are meat and milk), Uighur (mainly live in Xinjiang Uygur Autonomous Regions; the people of this ethnic group believe in Islam), and Mongolian (primarily live in Inner Mongolia; often being referred to as "the minority on horseback"; the staple foods are meat and milk). The age range of the volunteers was from 18 to $35 \mathrm{yr}$ old. The volunteers had no previous medical history of gastrointestinal diseases and had not taken any antibiotics $2 \mathrm{wk}$ before sampling. About $50 \mathrm{~g}$ of fecal sample was transferred with a sterile spoon into a sterile sampling tube marked with sampling site, date, and information on the volunteer. All the samples were frozen in liquid nitrogen after collection and rapidly transported to the laboratory by aircraft.

\section{Isolation and Identification of Bifidobacterium}

Isolation and Preliminary Identification of Bifidobacterium. About $1.0 \mathrm{~g}$ of human feces sample was well mixed in $9 \mathrm{~mL}$ of PBS $(8.0 \mathrm{~g}$ of $\mathrm{NaCl} / \mathrm{L}, 0.2 \mathrm{~g}$ of $\mathrm{KH}_{2} \mathrm{PO}_{4} / \mathrm{L}$, and $1.15 \mathrm{~g}$ of $\mathrm{Na}_{2} \mathrm{HPO}_{4} / \mathrm{L} ; \mathrm{pH}$ 7.2). Decimal serial anaerobic dilutions were prepared, and $1 \mathrm{~mL}$ of the appropriate diluents $\left(10^{-4}\right.$ and $\left.10^{-5}\right)$ was spread on triplicate sets of modified de Man, Rogosa, and Sharpe (MRS) and glucose-blood-liver (BL) selective media. The MRS medium (Difco lactobacilli MRS agar; Becton Dickinson, Pont-de-Claix, France) was modified by adding $100 \mu \mathrm{mol}$ of X-gal/L (Ferraris et al., 2010), $0.5 \%$ L-cystine, $10 \mu \mathrm{g}$ of cycloheximide $/ \mathrm{mL}$, and $2 \mathrm{~g}$ of $\mathrm{LiCl} / \mathrm{L}$. The selective BL medium (CM0785; Oxoid Ltd., Basingstoke, UK) was modified by adding neomycin sulfate $(100 \mu \mathrm{g} / \mathrm{mL})$, paromomycin sulfate $(200$ $\mu \mathrm{g} / \mathrm{mL})$, nalidixic acid $(15 \mu \mathrm{g} / \mathrm{mL})$, and cycloheximide $(10 \mu \mathrm{g} / \mathrm{mL})$. The inoculated agar plates were incubated under anaerobic conditions $\left(80 \% \mathrm{~N}_{2}, 10 \% \mathrm{H}_{2}\right.$, and $10 \%$ $\mathrm{CO}_{2}$ ) at $37^{\circ} \mathrm{C}$ for $48 \mathrm{~h}$ (Scardovi, 1986; Jousimies-Somer et al., 2002).

The colony characteristics of bifidobacteria were more typical in modified selective MRS or BL medium, so it was easy to distinguish them from other nonrelated bacteria (Kok et al., 1996). Bifidobacterial colonies were 
generally smooth, circular convex, marginal integrity, and were dark blue color on the modified MRS agar. On modified BL agar plates, they appeared as milky brown or milky white colonies of diameter between 0.6 and 1.8 $\mathrm{mm}$ (Scardovi, 1986). Single colonies with the described morphological characteristics were suspected to be Bifidobacterium and were randomly picked and inoculated into Trypticase peptone yeast extract (TPY) liquid enrichment medium using a sterile inoculating needle or loop. The pure cultures were incubated at $37^{\circ} \mathrm{C}$ for $24 \mathrm{~h}$ anaerobically. Gram-positive pure cultures were subject to a catalase test, fructose-6-phosphate phosphoketolase (F6PPK) activity detection, and further morphological observation. Detection of F6PPK activity in the cellular extracts was performed as described by Scardovi (1986). Cultures, which were catalase-negative, grampositive, non-spore forming, and F6PPK positive, were identified as bifidobacteria as described by Hadadji et al. (2005). To prepare frozen stocks, pure cultures of bifidobacteria were centrifuged at 3,000 $\times g$ for $10 \mathrm{~min}$ and washed 2 times with PBS, before being suspended in cryoprotective agent (10\% skim milk, $0.1 \%$ sodium glutamate, and $0.5 \%$ L-cysteine). These frozen stocks were stored at $-80^{\circ} \mathrm{C}$. Isolates were lyophilized for longterm storage.

Identification of Bifidobacterium by $16 S$ rRNA Gene Sequencing and Phylogenetic Analysis. Cells of Bifidobacterium grown overnight in modified MRS broth at $30^{\circ} \mathrm{C}$ were used for DNA extraction and purification as described by Liu et al. (2012). Two hundred microliters of purified DNA was diluted to 100 $\mathrm{ng} / \mu \mathrm{L}$ for $16 \mathrm{~S}$ rRNA amplification and sequencing. Amplification of the 16S rRNA sequences was carried out with an automatic thermal cycler (MJ Research PTC-200; MJ Research Inc., Watertown, MA) using the universal primers of the $16 \mathrm{~S}$ rRNA gene: $27 \mathrm{f}$ and $1495 \mathrm{r}$ (Lane, 1991; Delbès et al., 2007). The primer sequences $27 \mathrm{f}$ and $1495 \mathrm{r}$ were 5 '-AGAGTTTGATCCTGGCTCAG-3' and 5'-CTACGGCTACCTTGTTACGA-3', respectively. The PCR reaction mix was prepared similarly as described by Liu et al. (2012). The PCR amplifying conditions were as follows: $94^{\circ} \mathrm{C}$ for $5 \mathrm{~min}$, 31 cycles of $94^{\circ} \mathrm{C}$ for $1 \mathrm{~min}, 58^{\circ} \mathrm{C}$ for $1 \mathrm{~min}, 72^{\circ} \mathrm{C}$ for 2 min, and then $72^{\circ} \mathrm{C}$ for $8 \mathrm{~min}$ and left at $4^{\circ} \mathrm{C}$. The PCR products were electrophoresed on $1 \%$ agarose gel, and a DNA band of approximately 1,500 bp was obtained from all isolated strains. The DNA bands were excised, purified, and sequenced with an ABI Prism 3730XL DNA Analyzer (Applied Biosystems Inc., Foster City, CA) by Shanghai Sangni Biosciences Corporation of China (Shanghai, China). The DNA sequencing was performed twice to ensure accuracy. All sequences were then aligned using DNASTAR software package (DNASTAR Inc., Madison, WI).
Sequence similarity was checked across the GenBank database using the BLAST program (http://blast.ncbi. nlm.nih.gov/Blast.cgi). Phylogenetic tree construction and molecular evolutionary analyses were conducted using the neighbor-joining method within the MEGA version 4.0 package (Saitou and Nei, 1987; Kumar et al., 2004). All the obtained 16S rRNA sequences of isolates were compared with that of type strains of Bifidobacterium (B. pseudocatenulatum JCM1200 ${ }^{\mathrm{T}}$, B. longum ATCC $15707^{\mathrm{T}}$, B. breve ATCC15698 ${ }^{\mathrm{T}}$, B. catenulatum ATCC $27539^{\mathrm{T}}$, B. simiae CCUG30289 ${ }^{\mathrm{T}}$, B. dentium ATCC $27534^{\mathrm{T}}$, B. ruminantium JCM $8222^{\mathrm{T}}$, B. adolescentis ATCC $15703^{\mathrm{T}}$, B. bifidum DSM $20456^{\mathrm{T}}$, B. thermacidophilum DSM20083 ${ }^{\mathrm{T}}$, B. asteroides ATCC25910 ${ }^{\mathrm{T}}$, B. indicum JCM1302 ${ }^{\mathrm{T}}$, B. coryneforme ATCC25911 ${ }^{\mathrm{T}}$, B. pseudolongum JCM1205 ${ }^{\mathrm{T}}$, B. magnum JCM $1218^{\mathrm{T}}$, and B. minimum ATCC27538 ${ }^{\mathrm{T}}$ ) and an out-group strain (Escherichia coli ATCC11775 ${ }^{\mathrm{T}}$ ) to construct the phylogenetic tree.

\section{Preliminary Selection of Bifidobacterium}

Low $\boldsymbol{p H}$ Tolerance. Fresh cultures $(1.0 \mathrm{~mL})$ of Bifidobacterium cells were collected by centrifugation at $3,000 \times g$ for $10 \mathrm{~min}$, washed twice with PBS, and resuspended in saline solution to a final volume of 5 $\mathrm{mL}$. Then, $100 \mu \mathrm{L}$ of suspension was inoculated into 10 $\mathrm{mL}$ of MRS broth ( $\mathrm{pH} 2.0, \mathrm{pH} \mathrm{2.5}$, and 3.0). Optical density (OD) values were recorded at $620 \mathrm{~nm}$ after incubation in an anaerobic environment at $37^{\circ} \mathrm{C}$ for $48 \mathrm{~h}$. The resistant strains with survival rate over $98 \%$ were selected for further in vitro evaluation. Bifidobacterium animalis BB12 (Christian Hansen AS, Beijing, China), a probiotic strain, which could survive well in the presence of bile salt and had good acid tolerance, was used as a common reference strain (Dianawati and Shah, 2011). This strain was included in all the experiments of this study for comparison.

Transit Tolerance in Gastrointestinal Juices. The survival of Bifidobacterium in simulated gastrointestinal juices was determined according to the method described by Bao et al. (2010). Simulated gastric juice $(\mathrm{pH} 2.0$ and $\mathrm{pH} 2.5$ ) was inoculated with $1 \%$ fresh culture of the isolate to be tested and was incubated anaerobically at $37^{\circ} \mathrm{C}$. Total viable counts were determined at $0,1,2$, and $3 \mathrm{~h}$ of incubation. After $3 \mathrm{~h}$ of incubation in the gastric juice, $10 \%$ of the culture was inoculated into the simulated intestinal juice at $\mathrm{pH} 8.0$ and incubated anaerobically. Total viable counts were determined at 0,4 , and $8 \mathrm{~h}$ of incubation to evaluate the percentage survival in the intestinal juice. Total viable counts were determined by plating the serial dilutions on MRS agar and incubating anaerobically at $37^{\circ} \mathrm{C}$ for $48 \mathrm{~h}$. 
Bile Salt Tolerance of Bifidobacterium. The strains with the best tolerance in gastrointestinal juices were selected to test for their bile salt tolerance. The ability of the strains to grow in the presence of bile was determined according to the method of Vinderola et al. (2008) with some modifications: MRS broth cultures supplemented with 0.5 to $2.0 \%$ (wt/vol) oxgall (Oxoid Ltd.) were freshly prepared and inoculated with $1 \%$ ( $\mathrm{vol} / \mathrm{vol}$ ) overnight suspensions of the selected strains. Cultures were incubated anaerobically at $37^{\circ} \mathrm{C}$. The absorbance at $620 \mathrm{~nm}$ was measured and compared with the respective control culture without bile salts.

The tests were performed in round-bottom microwell plates (Nunclon). A $200-\mu \mathrm{L}$ volume each of MRS ( $\mathrm{pH}$ 2.5), MRS containing $0.3 \%$ oxgall, or normal MRS, was inoculated with the strain to be tested at a level of $10^{6}$ $\mathrm{cfu} / \mathrm{mL}$. The experiments were performed in quadruplicate. The culture broth without inoculation was used as the negative control. Changes in optical density at $620 \mathrm{~nm}\left(\mathrm{OD}_{620}\right)$ were measured (Multiscan MCC/340 photometer; Labsystem, Helsinki, Finland) following 0, $0.5,1,1.5,2,3,4,5,6,7$, and $24 \mathrm{~h}$ of incubation at $37^{\circ} \mathrm{C}$. Bacterial survival under the different conditions was determined after $4 \mathrm{~h}$ of incubation at $37^{\circ} \mathrm{C}$ by plate count of $100 \mu \mathrm{L}$ of the culture on MRS agar.

Bifidobacterium selected with high tolerance of artificial digestive juice were assessed in the next experiment. These selected strains were inoculated into modified MRS liquid medium with $2 \%$ (vol/vol) overnight suspensions of tested strains in MRS liquid medium containing bile salts (medium supplemented with 0.2 $\mathrm{g}$ of mercaptoacetate sodium/100 $\mathrm{g}$ and $0.3 \mathrm{~g}$ of bile salt/100 g) and non-bile-salt-modified MRS medium as a control; the cultures were incubated at $37^{\circ} \mathrm{C}$. The culture turbidity was recorded every hour by monitoring $O D$ values at $620 \mathrm{~nm}$. When the $\mathrm{OD}$ value increased by $0.3 \mathrm{U}$, the measurement of sample was stopped. The lag times for the selected isolates and the reference BB12 strain were determined. The lag time was defined as the difference between the times needed for the bacterial culture to increase by 0.3 OD units in the presence or absence of bile salts (Walker and Gilliland, 1993).

The highest bile salt concentration that could be tolerated by each tested strain was determined. Twopercent (vol/vol) inocula of tested strains were inoculated into modified MRS liquid medium supplemented with different bile salt concentrations $(0.3,0.6,0.8,1.0$, $1.5,1.8$, and $2.0 \%$ ), and then incubated anaerobically at $37^{\circ} \mathrm{C}$ for $24 \mathrm{~h}$. Absorbance values $(620 \mathrm{~nm}$ ) were measured at 0 and $12 \mathrm{~h}$. Meanwhile, the viable counts of each strain in the different concentration of bile salts were determined on the aforementioned MRS medium after $48 \mathrm{~h}$ of anaerobic growth at $37^{\circ} \mathrm{C}$. Each sample was prepared in triplicate.

\section{Fermentation and Storage Characteristics of Bifidobacterium in Bovine Milk}

Fermentation Characteristics of Selected Strains. The fermentation characteristics of selected strains were studied. Skimmed reconstituted milk was prepared by adding $1.5 \%$ of glucose into $10 \%$ skim milk. The milk was sterilized at $95^{\circ} \mathrm{C}$ for $10 \mathrm{~min}$ and cooled to $37^{\circ} \mathrm{C} ; 1 \times 10^{7} \mathrm{cfu} / \mathrm{mL}$ of the tested and the BB12 strains as the starter culture were separately inoculated into the prepared skim milk for fermentation at $37^{\circ} \mathrm{C}$. During the fermentation, samples were taken every 3 $\mathrm{h}$ to monitor the $\mathrm{pH}$, titratable acidity, and the total viable count of the tested strains. The fermentation was ended if the $\mathrm{pH}$ value was lower than 4.6 or the titratable acidity reached $80^{\circ} \mathrm{T}$. Parallel experiments were repeated 3 times.

Storage Characteristics of Fermented Milk by the Selected Strains. The fermented milk samples were stored in the refrigerator at $4^{\circ} \mathrm{C}$ for $21 \mathrm{~d}$. Samples were taken at 7,14 , and $21 \mathrm{~d}$. The $\mathrm{pH}$ value, titratable acidity, and total viable count of the tested strain were measured. Parallel experiments were repeated 3 times.

\section{Statistical Analysis}

Results were expressed as mean \pm standard deviation. Statistical significance was calculated by ANOVA supported by Student's $t$-test. Differences were considered significant at $P<0.05$.

\section{RESULTS AND DISCUSSION}

\section{Isolation and Identification of Bifidobacterium}

Twenty-nine isolates obtained from 18 samples were collected from different regions of ethnic groups of Henan (6 strains), Sichuan (11 strains), Tibet (7 strains), Xinjiang (1 strain), Yunnan (3 strains), and Inner Mongolia (1 strain), as shown in Table 1 . The isolates were identified by $16 \mathrm{~S}$ rRNA sequencing and phylogenetic analysis (Figure 1). The species identification of isolates was initially determined by the BLAST program (http://blast.ncbi.nlm.nih.gov/Blast.cgi), with more than $99 \%$ similarity compared with the $16 \mathrm{~S}$ rRNA sequences of type strains. Then, phylogenetic analysis including the representative strains and reference strains of each species was performed to reveal the species and distribution of the various isolates. Twentynine isolates and 17 type strains were clustered in 3 big groups presented in Figure 1, in which group I was regarded as the B. pseudocatenulatum group, including 19 isolates and type strains. Thus, these isolates were identified as B. pseudocatenulatum. The remaining isolates 
Table 1. Information of sample collection and identity of isolated Bifidobacterium

\begin{tabular}{lcclcc}
\hline \multirow{2}{*}{$\begin{array}{l}\text { Sampling } \\
\text { location } \\
\text { (province) }\end{array}$} & $\begin{array}{c}\text { Sample } \\
\text { number }\end{array}$ & $\begin{array}{c}\text { No. of volunteers } \\
\text { from city/country }\end{array}$ & $\begin{array}{l}\text { Ethnic } \\
\text { group }\end{array}$ & \multicolumn{2}{c}{ Isolated Bifidobacterium strain $^{1}$ (no.) } \\
\cline { 5 - 6 } & 5 & $3 / 2$ & Han & 6 & - \\
Henan & 6 & $3 / 3$ & Tujia & 2 & 9 \\
Sichuan & 5 & $3 / 2$ & Tibetan & - & B. pseudocatenulatum \\
Tibet & 1 & $0 / 1$ & Uyghur & 1 & 3 \\
Xinjiang & 1 & $0 / 1$ & Bai & - & 1 \\
Yunnan & 1 & $0 / 1$ & Mongolian & - & \\
Inner Mongolia & 1 & & &
\end{tabular}

1- indicates that no Bifidobacterium was isolated.

with high similarity to type strains of $B$. longum were identified as B. longum, indicated by group II. Group III contained only 1 strain (B. minimum ATCC $27538^{\mathrm{T}}$ ). Escherichia coli ATCC $11775^{\mathrm{T}}$ was included as an outgroup reference strain. Thus, in the present study, the isolated and identified bifidobacteria included 9 strains of B. longum and 20 strains of B. pseudocatenulatum. It is worth noting that 6 out of the $9 \mathrm{~B}$. longum strains were isolated in samples of Henan alone, from which no B. pseudocatenulatum was found. In contrast, samples from some other provinces, including Sichuan, Tibet, and Yunnan, were dominated by B. pseudocatenulatum, and $B$. longum was hardly isolated. The uneven species distribution may suggest that environmental factors such as the geographic location and regional diet were related to the microflora of the human gut, especially the composition of lactic acid bacteria and bifidobacteria.

Bifidobacterium are the crucial bacterial flora in maintaining a healthy human intestinal tract. In addition, the populations of Lactobacillus, Clostridium perfringens, and Enterococcus were also analyzed in the work by our research group (Sun, 2012). The results showed that the amounts of Lactobacillus and Bifidobacterium strains were significantly higher than that of $C$. perfringens and Enterococcus in the intestinal tract of healthy populations of Kazaks, Mongolians, and Tibetans in the provinces of Xinjiang and Tibet. It was also shown that the amounts of $C$. perfringens and Enterococcus in the intestinal tract of city residents were higher than those of the people living in the pastoral areas $(P<$ $0.05)$. Correlation analysis showed that the quantity of Enterococcus in the intestinal gut of healthy populations was negatively correlated with Lactobacillus and C. perfringens $(\mathrm{r}=-0.34, P=0.038 ; \mathrm{r}=-0.40, P=$ 0.011 , respectively), but was positively correlated $(\mathrm{r}=$ 0.68, $P<0.001$ ) with Bifidobacterium. In contrast, the amount of Bifidobacterium was negatively correlated with $C$. perfringens $(\mathrm{r}=0.77, P<0.001$; Sun, 2012). Thus, it can be deduced that an increase in the amount of Bifidobacterium in the intestinal tract can inhibit the growth of harmful bacteria such as C. perfringens.
It was previously reported that $B$. pseudocatenulatum and B. catenulatum were the most common bifidobacteria in the human intestine. They would be detected in approximately $92 \%$ of adults' fecal samples, followed by B. longum and B. adolescentis (Matsuki et al., 1999). Mullié et al. (2003) showed that B. longum and $B$. adolescentis were the major components of microflora in the intestinal tract of adults. Matsuki et al. (2004) studied the composition of the human intestinal bifidobacteria using quantitative PCR and fluorescence in situ hybridization methods and confirmed that B. pseudocatenulatum and B. catenulatum were the most common bifidobacteria in the intestinal tract of adults. Pang et al. (2005) analyzed the composition of bifidobacteria in healthy human guts of Chinese subjects by using the temperature gradient gel electrophoresis method. In their report, 9 out of 10 people were found to carry B. pseudocatenulatum; therefore, they presumed that B. pseudocatenulatum was a common strain in the healthy human gut in the Chinese population and proposed that it was the predominant strain. In the current study, mainly 2 species of Bifidobacterium were isolated and identified by pure culture method. Our results further confirmed that $B$. pseudocatenulatum and $B$. catenulatum were the most common and major species of Bifidobacterium in the intestinal tract of Chinese adults of different regions and ethnic groups.

\section{Low pH Tolerance}

The characteristic of tolerance of acid is a fundamental criterion for the selection for potential probiotic strains because of the low-pH environment of the stomach. It is the first challenge for the potential probiotic strains before they could successfully reach and colonize in the host gut. In most previous reports, $\mathrm{pH} 3.0$ was often used to assay the tolerance of probiotic strains in vitro (Renner, 1991; Liu et al., 2007). Over 80\% survival rate in gastric juice at $\mathrm{pH} 2.5$ for $3 \mathrm{~h}$ was regarded as a standard to select for potential probiotic organisms (Liu et al., 2007; Nawaz et al., 2011). In the stomach, the pH 


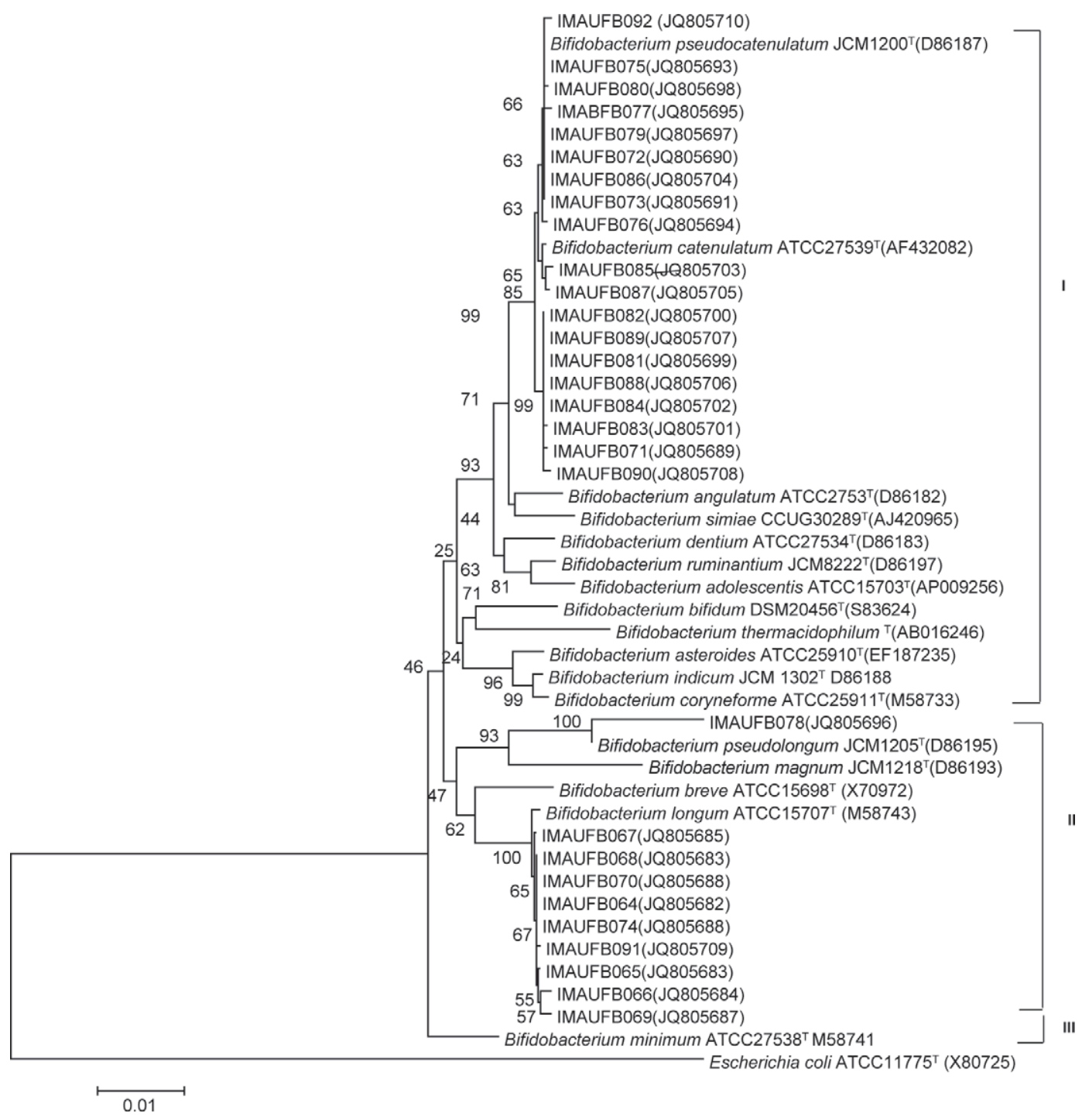

Figure 1. A $16 \mathrm{~S}$ rRNA-based phylogenetic tree of 30 Bifidobacterium isolates and 17 type strains.

value can decrease to 1.0. However, the presence of food raises the $\mathrm{pH}$ value to 3.0 , and the food transition time through the human stomach is about 90 min (Renner, 1991; Erkkilä and Petäjä, 2000). Therefore, probiotic strains are not likely to be exposed to the extremes of $\mathrm{pH}$ in the stomach because of the buffering effect of the ingested foods or other carrier matrix molecules following consumption. In the current study, we evaluated the ability of the isolated strains to tolerate low $\mathrm{pH}(\mathrm{pH}$ $3.0,2.5$, and 2.0). Twenty-five out of 29 strains (86\%) were able to grow well in $\mathrm{pH} 3.0$ for $3 \mathrm{~h}$. The survival rates of these strains were more than $96 \%$. The selection was further carried out based on their growth at $\mathrm{pH} 2.5$ and $\mathrm{pH} 2.0$, respectively. Fifteen strains showed high survival rates (over 90\%) after being treated at $\mathrm{pH} 2.5$ for $3 \mathrm{~h}$ (data not shown). Among them, only 4 strains (namely IMAUFB084, IMAUFB064, IMAUFB073, and IMAUFB077) showed relatively high survival rates of over $50 \%$ after being treated at $\mathrm{pH} 2.0$ for $3 \mathrm{~h}$. Our results also showed that these 4 strains were even more acid resistant than the reference strain used in this study (Bifidobacterium animalis $\mathrm{ssp}$. lactis BB12). The strain BB12 was used previously in our laboratory as the reference strain for probiotic strain selection and characteristic comparison, and it showed a high level of tolerance to gastric acid and bile acids (Wang et al., 2009). This probiotic strain has been used in the industrial production of dairy starter cultures by many large dairy corporations in China and other countries. Further tests on the abilities of transit gastrointestinal tract and bile tolerance were performed on these 4 isolates from the current study. 
Table 2. Viable counts and survival rates of 8 strains of Bifidobacterium in artificial gastric juice at $\mathrm{pH} 2.0$ for different periods of time ${ }^{1}$

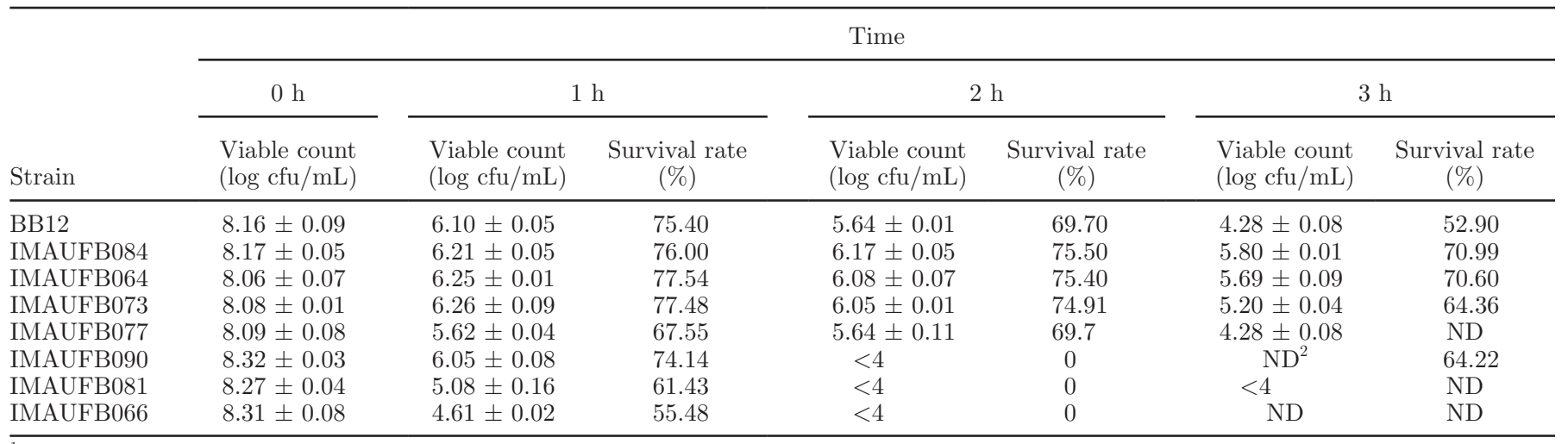

${ }^{1}$ Data are presented as mean \pm SD from triplicate experiments.

${ }^{2} \mathrm{ND}=$ not detected.

\section{Survival in Gastrointestinal Juices}

The strains with the ability to tolerate low $\mathrm{pH}$ were further tested for their transit tolerance in artificial gastric and intestinal juices at $\mathrm{pH} 2.0$ and $\mathrm{pH}$ 8.0, respectively. Results from the transit tolerance test are listed in Table 2. The viable counts of these 4 selected strains were more than $6.60 \pm 0.03 \mathrm{log} \mathrm{cfu} / \mathrm{mL}$ when they were cultured in artificial gastric juice at $\mathrm{pH} 2.0$ for $3 \mathrm{~h}$. The survival rates of all 4 strains were over $80 \%$, and IMAUFB084 was the most acid tolerant, with a $85.98 \%$ survival rate at $\mathrm{pH} 2.0$ for $3 \mathrm{~h}$. Our results showed that these 4 strains could tolerate the simulated digestive juice at $\mathrm{pH} 8.0$ for $8 \mathrm{~h}$ (Table 3 ); the survival rates of all strains were more than $96 \%$ after being cultured in artificial intestinal juice at $\mathrm{pH} 8.0$ for $4 \mathrm{~h}$. After culturing for $8 \mathrm{~h}$ in the same simulative digestive juice, the survival rate of these strains generally decreased slightly but remained over $89 \%$. The strain IMAUFB090 had the highest tolerance to the artificial intestinal juice, with $97.86 \%$ survival rate at $\mathrm{pH} 8.0$ for $8 \mathrm{~h}$. It was shown that these 4 selected strains could survive well after a sequential passage and prolonged exposure to the simulated gastric and intestinal juices. Therefore, it is likely that these human origin isolates could successfully transit through the stomach and reach the intestinal environment to function there effectively.

\section{Bile Salt Tolerance}

It is generally considered to be necessary to evaluate the ability of lactobacilli and bifidobacteria to resist the effects of bile acids when screening for potentially effective probiotics (Lee and Salminen, 1995; Dunne et al., 2001). The bile tolerance of the 4 gastrointestinal juice resistant strains in the presence of different concentrations of bile salts is listed in Table 4, and the lag time of bile tolerance of these strains is shown in Table 5. The bacteria were considered to be bile salt resistant if the survival rate remained over $50 \%$ after being cultured for $12 \mathrm{~h}$ at $37^{\circ} \mathrm{C}$ at the specific bile salt concentration. Among the 4 selected strains, all of them could survive well at $0.8 \%$ bile salts, 3 of them could tolerate up to $1.8 \%$ bile salts, and only 1 strain (IMIUFB084) could tolerate a high concentration of $2.0 \%$ bile salts. Four strains could grow in $1.0 \%$ bile salt. However, the delay of growth (lag time) of these 4 strains were 0.59, 0.76, 0.77 , and $0.96 \mathrm{~h}$, respectively (shown in Table 5). According to Chateau et al. (1994), bile salt resistance

Table 3. Survival of 5 strains of Bifidobacterium in artificial gastric and intestinal juices

\begin{tabular}{|c|c|c|c|c|c|c|c|c|}
\hline Strain & \multicolumn{3}{|c|}{ Artificial gastric juice at $\mathrm{pH} 2.0$} & \multicolumn{5}{|c|}{ Artificial intestinal juice at $\mathrm{pH} 8.0$} \\
\hline BB12 & $8.25 \pm 0.05$ & $7.05 \pm 0.04$ & 85.45 & $6.01 \pm 0.02$ & $5.94 \pm 0.05$ & $5.88 \pm 0.05$ & 98.84 & 97.84 \\
\hline IMAUFB084 & $8.20 \pm 0.04$ & $7.05 \pm 0.02$ & 85.98 & $6.05 \pm 0.08$ & $5.97 \pm 0.11$ & $5.71 \pm 0.03$ & 98.68 & 94.38 \\
\hline IMAUFB073 & $8.23 \pm 0.06$ & $7.05 \pm 0.04$ & 85.66 & $6.05 \pm 0.05$ & $5.89 \pm 0.08$ & $5.88 \pm 0.02$ & 97.36 & 97.19 \\
\hline
\end{tabular}

\footnotetext{
${ }^{1}$ Data are presented as mean \pm SD from triplicate experiments.
} 
Table 4. Bile salt tolerance of 5 strains of Bifidobacterium at different bile salt concentrations ${ }^{1}$

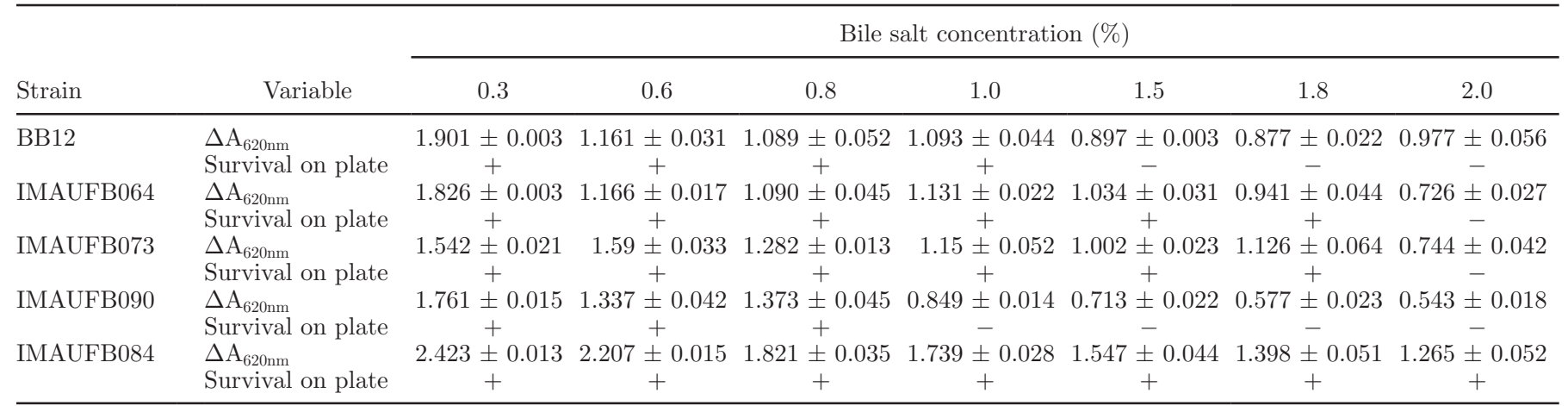

${ }^{1}+$ and - indicate that the survival rate of the strain was, respectively, $>50 \%$ or $<50 \%$ after culturing for $12 \mathrm{~h}$ at $37^{\circ} \mathrm{C}$ on de Man, Rogosa, and Sharpe (MRS) agar plates containing the specific concentration of bile salts; $\Delta \mathrm{A}_{620 \mathrm{~nm}}$ is the change in absorbance at $620 \mathrm{~nm}(\mathrm{n}=3 ;$ mean $\pm \mathrm{SD})$.

could be classified by the delay of growth or lag time in the presence of oxgall compared with its normal growth. Resistant, tolerant, weakly tolerant, and sensitive strains have delay of growth $(d)$ or lag time of $<15 \mathrm{~min}, 15<d \leq 40 \mathrm{~min}, 40<d \leq 60 \mathrm{~min}$ and $d$ $>60 \mathrm{~min}$, respectively. The delay of growth or the lag time for IMAUFB064, IMAUFB084, IMAUFB090, and IMAUFB073 were determined to be $35.4,45.6,46.2$, and $57.6 \mathrm{~min}$, respectively. From these results, only the reference strain BB12 but not any of the other Bifidobacterium isolates could be classified as a resistant strain. The isolate IMAUFB064 fell into the group of bile salt tolerance, whereas IMAUFB084, IMAUFB090, and IMAUFB073 were only weakly tolerant.

\section{Fermentation and Storage Characteristics of Bifidobacterium in Bovine Milk}

Two other important characteristics of potential fermentation starter culture strains are their efficiency in fermentation as indicated by the decrease in $\mathrm{pH}$ and increase in titratable acidity, as well as a high viability and a long survival time during the shelf life of the fermented products. Therefore, these are also vital selection criteria tested in this study. In the fermentation experiments, all strains presented good acid-producing ability, as the average $\mathrm{pH}$ declined from about 6.45 to below 4.5 and the titratable acidity increased from 15 ${ }^{\circ} \mathrm{T}$ to over $80^{\circ} \mathrm{T}$ during fermentation at $37^{\circ} \mathrm{C}$ for $21 \mathrm{~h}$ in bovine milk (Figure 2). Strain IMAUFB073 showed a high efficiency of acid production, as only $18 \mathrm{~h}$ were needed to end the fermentation at the same temperature.

To test the survival of these bacteria during product shelf life, the viability of these strains in the fermented bovine milk was followed for $21 \mathrm{~d}$. It was found that, generally, the $\mathrm{pH}$ of the fermented bovine milks slightly decreased from about $\mathrm{pH} 4.5$ to $\mathrm{pH} 4.36$ (Figure 3). The $\mathrm{pH}$ of the fermented milk made by strain BB12 declined more than that of the others and was up to a $\mathrm{pH}$ change of 0.22 , whereas the $\mathrm{pH}$ decline of fermented milks made with the 4 other strains (IMAUFB064, IMAUFB073, IMABUFB090, and IMAUFB084) were $0.12,0.12,0.12$, and 0.13 , respectively. During the first $7 \mathrm{~d}$ of storage, the $\mathrm{pH}$ change was similar and was mild in fermented milks produced by all the strains. The

Table 5. Bile tolerance (lag time) of 5 Bifidobacterium strains to $0.3 \%$ bile salts ${ }^{1}$

\begin{tabular}{|c|c|c|c|}
\hline \multirow[b]{2}{*}{ Strain } & \multicolumn{3}{|c|}{ Absorbance at $620 \mathrm{~nm}$ measured per hour ${ }^{2}$} \\
\hline & $\begin{array}{c}\text { Modified } \\
\text { MRS-mercaptoacetate } \\
\text { sodium }\end{array}$ & $\begin{array}{c}\text { Modified } \\
\text { MRS-mercaptoacetate } \\
\text { sodium + oxgall }\end{array}$ & $\begin{array}{l}\text { Lag time } \\
\quad(\mathrm{h})\end{array}$ \\
\hline BB12 & $1.86 \pm 0.16$ & $2.11 \pm 0.09$ & $0.25 \pm 0.07^{\mathrm{d}}$ \\
\hline IMAUFB064 & $1.82 \pm 0.08^{\mathrm{b}}$ & $2.41 \pm 0.11^{\mathrm{c}}$ & $0.59 \pm 0.03^{\mathrm{c}}$ \\
\hline IMAUFB084 & $2.07 \pm 0.36^{\mathrm{a}}$ & $2.83 \pm 0.25^{\mathrm{a}}$ & $0.76 \pm 0.09^{\mathrm{b}}$ \\
\hline IMAUFB090 & $1.81 \pm 0.25^{\mathrm{b}}$ & $2.58 \pm 0.34^{\mathrm{b}}$ & $0.77 \pm 0.09^{\mathrm{b}}$ \\
\hline IMAUFB073 & $1.82 \pm 0.35^{\mathrm{b}}$ & $2.78 \pm 0.27^{\mathrm{a}}$ & $0.96 \pm 0.08^{\mathrm{a}}$ \\
\hline
\end{tabular}


A

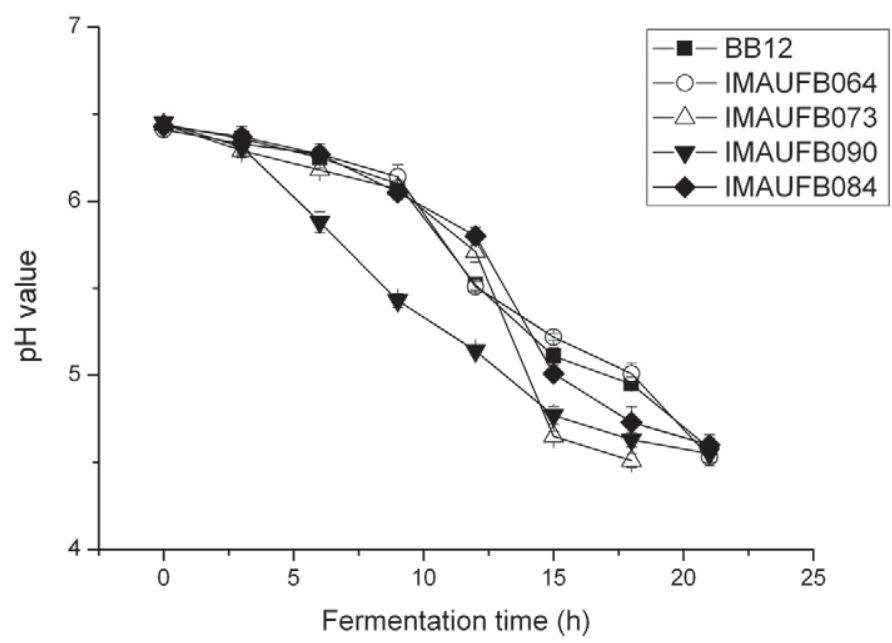

B

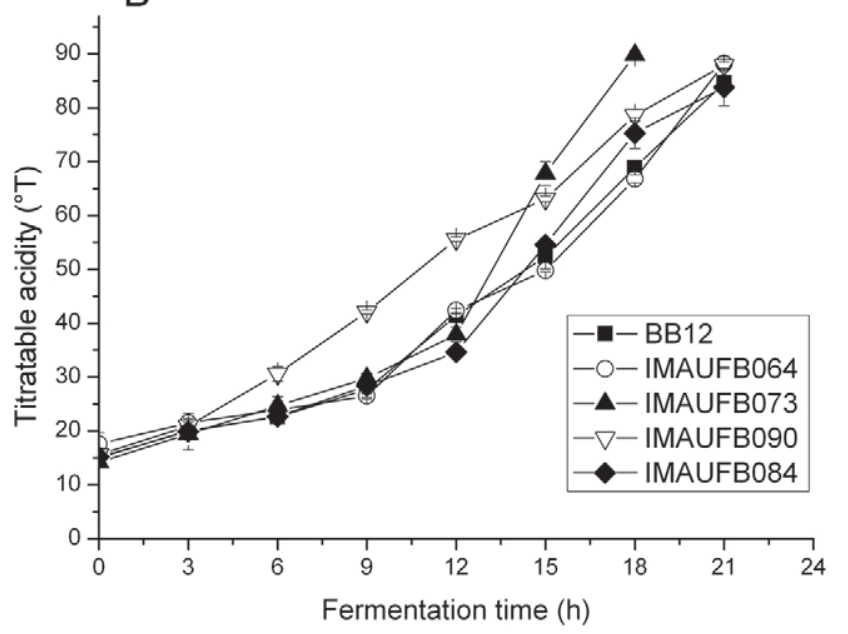

Figure 2. Change of $\mathrm{pH}$ and titratable acidity during fermentation of bovine milk by various selected Bifidobacterium isolates and Bifidobacterium animalis BB12.

titratable acidity of the isolates from the current study increased by about $10^{\circ} \mathrm{T}$, which was lower than that of the BB12 reference strain (increased by $20.1^{\circ} \mathrm{T}$ ).

The changes in viable counts of bifidobacteria in the fermented bovine milks during storage for $21 \mathrm{~d}$ at $4^{\circ} \mathrm{C}$ are shown in Figure 4. Compared with the initial inoculation, the number of viable cells in all the fermented milks significantly increased when the fermentation reached the end. At the end of the fermentation, the viable counts of the fermented milks made with the reference BB12 strain and the Bifidobacterium isolates IMAUFB064, IMAUFB090, IMAUFB073, and IMAUFB084 were $5.13 \times 10^{8}, 3.33 \times 10^{8}, 5.44 \times 10^{8}$, $6.02 \times 10^{8}$, and $3.91 \times 10^{8} \mathrm{cfu} / \mathrm{mL}$, respectively. During the $21 \mathrm{~d}$ of storage, the viable counts of all strains were not significantly decreased. During the first 7 $\mathrm{d}$, the viable counts of bacteria BB12, IMAUFB084, and IMAUFB064 did not decline, but increased. Only the number of viable cells of the strain IMAUFB073 had a small decrease, whereas viable counts of the strain IMAUFB090 remained unchanged. After $14 \mathrm{~d}$ of storage, the viable counts of all the strains began to decrease, except for the reference strain BB12, which remained stable. But even strain IMAUFB084 exhibited a small decrease in viable count.

\section{CONCLUSIONS}

Twenty-nine human-originated Bifidobacterium strains were isolated and identified as B. longum and B. pseudocatenulatum by $16 \mathrm{~S}$ rRNA gene sequencing and phylogenetic analysis. Preliminary in vitro tolerance tests, including acid, simulated gastrointestinal juice, and bile salt tolerance, were performed to evaluate the ability of these strains to survive in the diverse environment within the digestive tract. Twenty-five out of 29 strains $(86 \%)$ were able to grow well at $\mathrm{pH} 3.0$ for $3 \mathrm{~h}$; however, only 7 of them could tolerate even lower acidity at $\mathrm{pH} 2.0$ for $3 \mathrm{~h}$. When further tests were carried out, only 4 out of these 7 strains exhibited

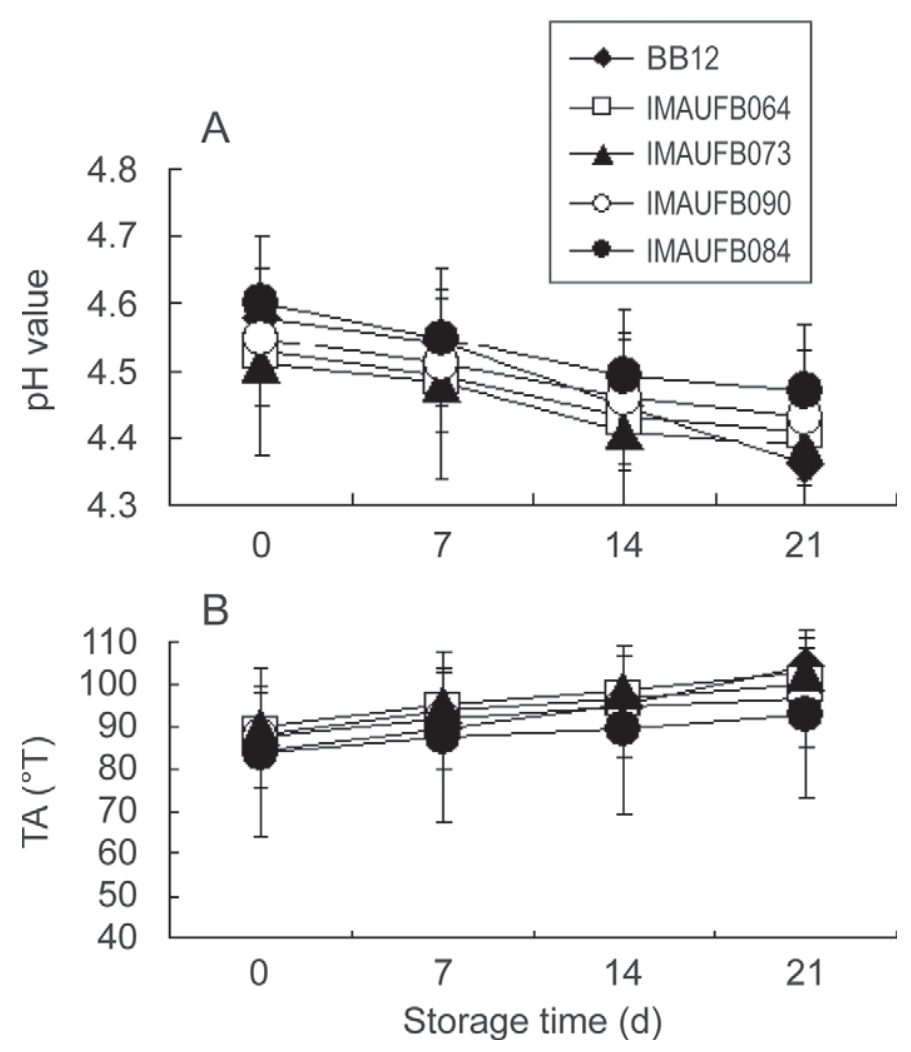

Figure 3. Changes of $\mathrm{pH}$ and titratable acidity (TA) during storage of fermented bovine milks produced by various selected Bifidobacterium isolates and Bifidobacterium animalis BB12. 


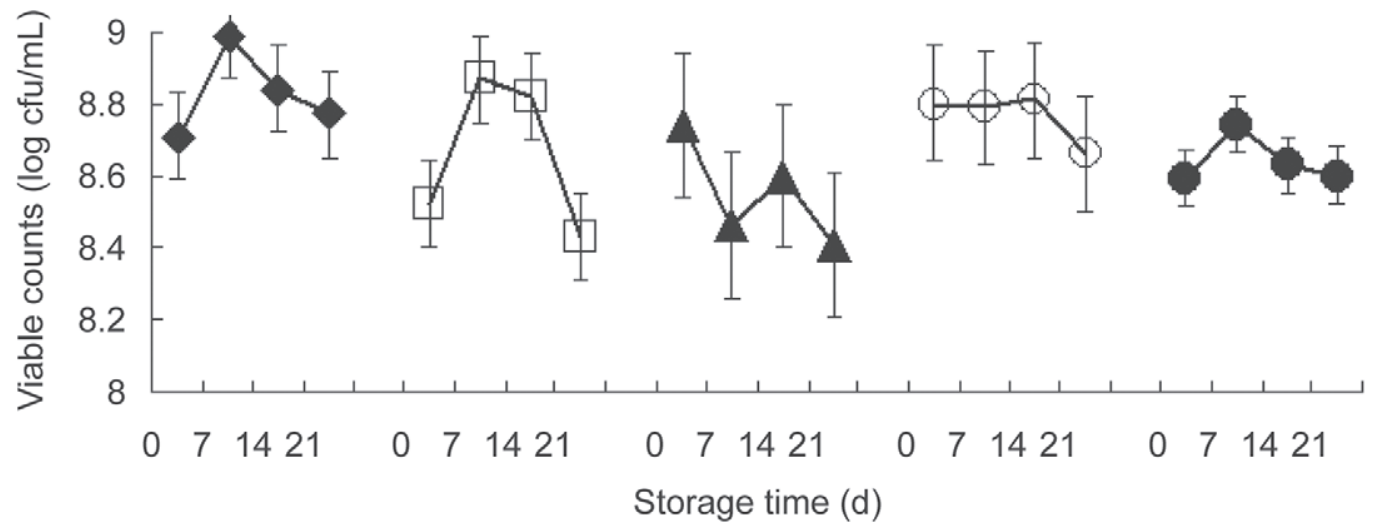

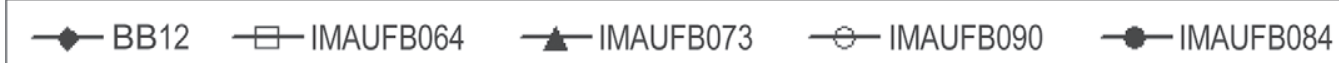

Figure 4. Change in viable counts of Bifidobacterium strains during storage of fermented milks.

good resistance to gastrointestinal transit and bile salt tolerance. Among these 4 strains, B. pseudocatenulatum IMAUFB084 showed the best tolerance to acidity, bile salts, and simulated gastrointestinal juices. Moreover, all 4 strains showed good fermentation and storage characteristics in bovine milk. The fermentation time needed for these strains was less than $21 \mathrm{~h}$, and was as short as only $18 \mathrm{~h}$ for strain IMAUFB073. The viable counts of these strains in fermented bovine milk were more than $3 \times 10^{8} \mathrm{cfu} / \mathrm{mL}$ at the end of the fermentation, and their viability did not significantly decline during longer term storage at $4^{\circ} \mathrm{C}$ for $21 \mathrm{~d}$. Taken together, our study isolated novel strains that may serve as important resources for further dairy probiotic strain selection.

\section{ACKNOWLEDGMENTS}

This work was supported by the National Science Fund for Distinguished Young Scholars of China (Beijing, China; Grant No. 31025019), Innovation Research Team Development Program of Ministry of Education of China (Beijing, China; Grant No. IRT0967), National Science Fund of China (Beijing, China; Grant No. 31101315), China Agriculture Research System (CARS-37), Natural Science Foundation for Open Projects of Inner Mongolia (Grant No. 20102010), and Key Laboratory Major Open Project Fund of Inner Mongolia (Grant No. 20130902).

\section{REFERENCES}

Bao, Y., Y. Zhang, Y. Liu, S. Q. Wang, X. Dong, Y. Wang, and H. Zhang. 2010. Screening of potential probiotic properties of Lactobacillus fermentum isolated from traditional dairy products. Food Contr. 21:695-701.
Chateau, N., A. M. Deschamps, and A. Hadj Sassi. 1994. Heterogeneity of bile salts resistance in the Lactobacillus isolates of a probiotic consortium. Lett. Appl. Microbiol. 18:42-44.

Conway, P. L., S. L. Gorbach, and B. R. Goldin. 1987. Survival of lactic acid bacteria in the human stomach and adhesion to intestinal cells. J. Dairy Sci. 70:1-12.

Dave, R. I., and N. P. Shah. 1996. Evaluation of media for selective enumeration of Streptococcus thermophilus, Lactobacillus delbrueckii ssp. bulgaricus, Lactobacillus acidophilus, and Bifidobacteria. J. Dairy Sci. 79:1529-1536.

Delbès, C., L. Ali-Mandjee, and M.-C. Montel. 2007. Montel monitoring bacterial communities in raw milk and cheese by culturedependent and independent 16S rRNA gene-based analyses. Appl. Environ. Microbiol. 73:1882-1891.

Del Piano, M., L. Morelli, G. P. Strozzi, S. Allesina, M. Barba, F. Deidda, P. Lorenzini, M. Ballaré, F. Montino, M. Orsello, M. Sartori E. Garello, S. Carmagnola, M. Pagliarulo, and L. Capurso. 2006. Probiotics: From research to consumer. Dig. Liver Dis. 38:S248 S255.

Dianawati, D., and N. P. Shah. 2011. Survival, acid and bile tolerance, and surface hydrophobicity of microencapsulated B. animalis ssp. lactis Bb12 during storage at room temperature. J. Food Sci. 76:M592-M599.

Dunne, C., L. O'Mahony, L. Murphy, G. Thornton, D. Morrissey, S. O'Halloran, M. Feeney, S. Flynn, G. Fitzgerald, and C. Daly. 2001. In vitro selection criteria for probiotic bacteria of human origin: Correlation with in vivo findings. Am. J. Clin. Nutr. 73:386S$392 \mathrm{~S}$.

Erkkilä, S., and E. Petäjä. 2000. Screening of commercial meat starter cultures at low $\mathrm{pH}$ and in the presence of bile salts for potential probiotic use. Meat Sci. 55:297-300.

FAO/WHO (Food and Agriculture Organization of the United Nations/World Health Organization). 2001. Health and nutritional properties of probiotics in food including powder milk with live lactic acid bacteria. FAO and WHO Expert Consultation report. Accessed Dec. 2012. ftp://ftp.fao.org/docrep/fao/meeting/009/ y6398e.pdf.

Ferraris, L., J. Aires, A.-J. Waligora-Dupriet, and M.-J. Butel. 2010 New selective medium for selection of bifidobacteria from human feces. Anaerobe 16:469-471.

Hadadji, M., R. Benama, N. Saidi, D. E. Henni, and M. Kihal. 2005. Identification of cultivable Bifidobacterium species isolated from breast-fed infants feces in West-Algeria. Afr. J. Biotechnol. 4:422-430.

Jousimies-Somer, H. R., P. Summanem, D. M. Citron, E. J. Baron, H. M. Wexler, and S. M. Finegold. 2002. Anaerobic Bacteriology Manual. Star Publishing Co., Belmont, CA. 
Kok, R. G., A. de Waal, F. Schut, G. W. Welling, G. Weenk, and K. J. Hellingwerf. 1996. Specific detection and analysis of a probiotic Bifidobacterium strain in infant feces. Appl. Environ. Microbiol. 62:3668-3672.

Kumar, S., K. Tamura, and M. Nei. 2004. MEGA3: Integrated software for molecular evolutionary genetics analysis and sequence alignment. Brief. Bioinform. 5:150-163.

Lane, D. J. 1991. 16S/23S rRNA sequencing. Pages 115-175 in Nucleic Acid Techniques in Bacterial Systematics. E. Stackebrandt and M. Goodfellow, ed. Wiley, Chichester, UK.

Lee, Y.-K., and S. Salminen. 1995. The coming age of probiotics. Trends Food Sci. Technol. 6:241-245.

Liu, W., Q. Bao, Jirimutu, M. Qing, Siriguleng, X. Chen, T. Sun, M. Li, J. Zhang, J. Yu, M. Bilige, T. Sun, and H. Zhang. 2012. Isolation and identification of lactic acid bacteria from Tarag in Eastern Inner Mongolia of China by $16 \mathrm{~S}$ rRNA sequences and DGGE analysis. Microbiol. Res. 167:110-115.

Liu, Z., Z. Jiang, K. Zhou, P. Li, G. Liu, and B. Zhang. 2007. Screening of bifidobacteria with acquired tolerance to human gastrointestinal tract. Anaerobe 13:215-219.

Matsuki, T., K. Watanabe, J. Fujimoto, Y. Kado, T. Takada, K. Matsumoto, and R. Tanaka. 2004. Quantitative PCR with 16S rRNA gene targeted species specific primers for analysis of human intestinal bifidobacteria. Appl. Environ. Microbiol. 70:167-173.

Matsuki, T., K. Watanabe, R. Tanaka, M. Fukuda, and H. Oyaizu. 1999. Distribution of bifidobacterial species in human intestinal microflora examined with $16 \mathrm{~S}$ rRNA-gene-targeted species-specific primers. Appl. Environ. Microbiol. 65:4506-4512.

Mullié, C, M.-F. Odou, E. Singer, M.-B. Romond, and D. Izard. 2003. Multiplex PCR using 16SrRNA gene-targeted primers for the identification of bifidobacteria from human origin. FEMS Microbiol. Lett. 222:129-136.

Nawaz, M., J. Wang, A. Zhou, C. Ma, X. Wu, and J. Xu. 2011. Screening and characterization of new potentially probiotic lactobacilli from breast-fed healthy babies in Pakistan. Afr. J. Microbiol. Res. 5:1428-1436.

Pang, X. Y., B. R. Zhang, G. F. Wei, and L. P. Zhao. 2005. Analysis of bifidobacteria spp. composition in human gut via temperature gradient gel electrophoresis (TGGE). Wei Sheng Wu Xue Bao 45:738-743.
Picard, C., J. Fioramonti, A. Francois, T. Robinson, F. Neant, and C. Matuchansky. 2005. Review article: Bifidobacteria as probiotic agents-Physiological effects and clinical benefits. Aliment. Pharmacol. Ther. 22:495-512.

Playne, M. 1994. Probiotic foods. Food Aust. 46:362-366.

Renner, E. 1991. Cultured dairy products in human nutrition. Bull. Int. Dairy Fed. 255:2-24

Saitou, N., and M. Nei. 1987. The neighbor-joining method: A new method for reconstructing phylogenetic trees. Mol. Biol. Evol. $4: 406-425$

Samona, A., and R. K. Robinson. 1991. Enumeration of bifidobacteria in dairy products. Int. J. Dairy Technol. 44:64-66.

Scardovi, V. 1986. Genus Bifidobacterium. Pages 1418-1434 in Bergey's Manual of Systematic Bacteriology. Vol. 2. H. A. P. Sneath N. S. Mair, M. E. Sharpe, and J. G. Holt, ed. Williams and Wilkins, Baltimore, MD

Shah, N., and P. Jelen. 1990. Survival of lactic acid bacteria and their lactases under acidic conditions. J. Food Sci. 55:506-509.

Shah, N. P. 2000. Probiotic bacteria: Selective enumeration and survival in dairy foods. J. Dairy Sci. 83:894-907.

Sun, T. 2012. Isolation and Identification of Lactobacillus from human intestine and study on their resistant ability and fermentation characteristics. Master's Thesis. Inner Mongolia Agricultural University, Hohhot, Inner Mongolia, China.

Vinderola, C. G., N. Bailo, and J. A. Reinheimer. 2000. Survival of probiotic microflora in Argentinian yoghurts during refrigerated storage. Food Res. 33:97-102.

Vinderola, G., B. Capellini, F. Villarreal, V. Suárez, A. Quiberoni, and J. Reinheimer. 2008. Usefulness of a set of simple in vitro tests for the screening and identification of probiotic candidate strains for dairy use. Lebensm. Wiss. Technol. 41:1678-1688.

Walker, D. K., and S. E. Gilliland. 1993. Relationship among bile tolerance, bile salt deconjugation, and assimilation of cholesterol by Lactobacillus acidophilus. J. Dairy Sci. 76:956-961.

Wang, J., Z. Guo, Q. Zhang, L. Yan, W. Chen, X.-M. Liu, and H.-P. Zhang. 2009. Fermentation characteristics and transit tolerance of probiotic Lactobacillus casei Zhang in soymilk and bovine milk during storage. J. Dairy Sci. 92:2468-2476. 